DEPARTAMENTO DE ANATOMIA DESCRITIVA DOS ANIMAIS DOMESTCOS

Diretor: Prol. Dr. Orlando M. Palva

\title{
COMPORTAMENTO DA ANSA SPIRALIS DO COLON NO VEADO MATEIRO (MAZAMA AMERICANA)
}

\author{
(THE ARRANGEMENT OF THE ANSA SPIRALIS OF THE
}

COLON IN MAZAMA AMERICANA)

VICENTE BORELLI

Prof. Assistente Doutor
JOSE PEDUTI NETO

Pror. Assistente
I. L. DE SANTIS PRADA
Prof. Assistente Doutor

\section{INTRODUÇÃO E LITERATURA}

O presente trabalho tem a finalidade de registrar variações no grau de enrolamento da ansa spiralis em ruminantes selvagens, bem como a ocorrência de irregularidades na disposição das voltas dessa seç̧ão do intestino grosso, uma vez que, em outras oportunidades, já assinalamos o comportamento da alça convoluta em animais domésticos, isto é, em bovinos de origem indiana (PAIVA \& BORELLI - 1963/64 - a, b, c) ou européia (BORELLI \& PEDUTI NETO 1966 - a, b), em caprinos (BORELLI \& D'ERRICO - 1965; BORELLI \& FERNANDES FILHO - 1965; PAIVA \& BORELLI 1965), em ovinos (PAIVA \& BORELLI - 1966; BORELLI \& SANTIS PRADA - 1966/67) e, mais recentemente, em búfalos (PEDUTI NETO, BORELLI \& BOCALLETTI - 1970).

Quanto aos ruminantes selvagens e, particularmente no que tange ao veado mateiro, não pudemos coligir, na literatura consultada, qualçuer informação alusiva aos particulares aspectos morfológicos considerados nesta pesquisa.

\section{MATERIAL E MÉTODO}

Examinamos 4 tratcs intestinais correspondentes a 2 fêmeas (adultas) e 2 machos ( 1 jovem e 1 feto), obtidos no Parque Zoológico da Cidade de Deus (S. P.). Registramos o comportamento dos circuitos, abordados pela esquerda, contando os regulares à maneira de SMITH (1955) e classificando as irregularidades segundo os padrões adotados por PAIVA \& BORELLI (1963/64-a). 


\section{RESULTADOS}

Dos 4 cólons observados, 2 dêles, correspondentes a 1 fêmea e 1 macho (feto) apresentaram disposição regular identificando-se 1 peça (macho) com três e meio giros sucessivamente centrípetos e centrífugos e, 1 outra (fêmea), com três e meio e quatro voltas, por ordem, de entrada e de saída. Em 2 casos, relativos a 1 fêmea e 1 macho (jovem), surpreendemos espiralamento imperfeito do cólon convoluto. Assim, no primeiro dêles, a exibir dois circuitos concêntricos e dois e meio excêntricos, o defeito instalou-se na terceira meia curva centrípeta (Fig. 1), enquanto no segundo, com três e meio e quatro lances respectivamente proximais e distais, evidenciamos a irregularidade inserida na sétima meia volta de saída (Fig. 2).

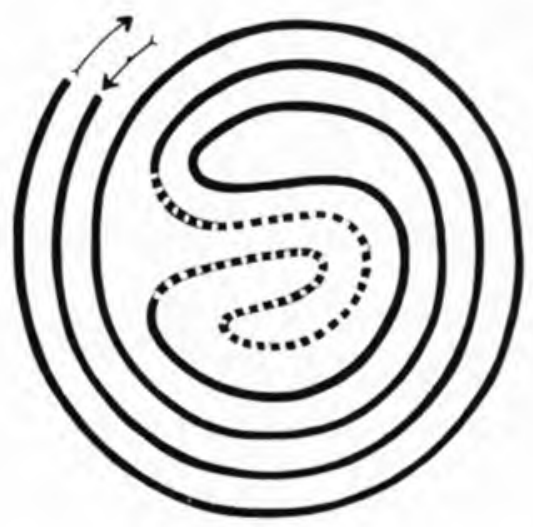

FIG. 1

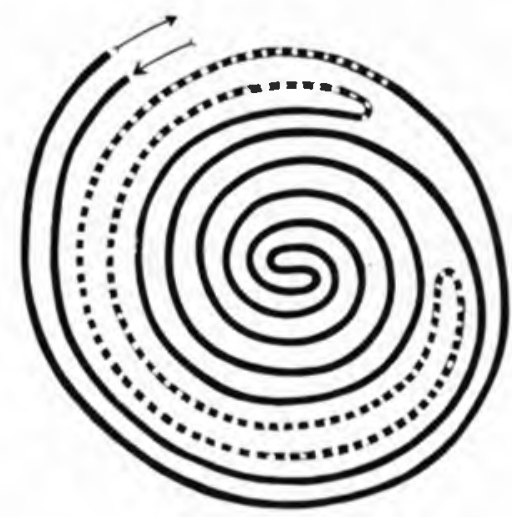

FIO. 2

Fugs. 1 e 2 - Disposiçઠes Incomuns da ansa splralls do cólon, no veado mateiro (Mazama americana). 


\section{COMENTARIOS E CONCLUSOES}

Os resultados obtidos revelaram que o veado mateiro apresenta também variações quanto ao número de alças concêntricas do cólon convoluto, já que nos foi possivel verificar a presença de duas espiras perfeitas exibindo, uma delas, três e três e meio giros, por ordem, centrípetas e centrífugas e, a outra, três e meia e quatro curvas respectivamente de entrada e de saida. Por outro lado, êles nos permitiram saber da possibilidade de ocorrência de irregularidades no volteamento do focado trato intestinal; de fato, surpreendemos, em 2 casos, presença de defeito inserido na terceira meia curva de entrada,em alça com dois circuitos concêntricos e dois e meio excêntricos e, na sétima meia volta de saída, em espira com três e meio lances proximais e quatro distais.

Contudo não seja lícito estabelecer contronto direto dos achados desta pesquisa com as informações contidas em nossos trabalhos sôbre o assunto, anteriormentr realizados (PAIVA \& BORELLI 1963/64 a, b, c; BORELLI \& PEDUTI NETO - 1966 a, b; BORELLI \& D'ERRICO; BORELLI \& FERNANDES FILHO; PAIVA \& BORELLI - 1966; BORELLI \& SANTIS PRADA; PEDUTI NETO, BORELLI \& BOCALLETTI), por referirem-se a diferentes espécies, julgamos de interêsse salientar que, levados em conta e à parte, o grupo dos grandes e dos pequenos ruminantes, a ansa spiralis dos exemplares examinados exibe aspectos semelhantes aos do cólon convoluto dos últimos, tais sejam, o maior número de arcos centrípetos e centrífugos, o afastamento da última curva de saída e, ainda afirmativa que fazemos com ressalva, dado o pequeno tamanho da amostra -, a alta incidência de cólons portadores de vícios de conformação.

\section{SUMMARY}

The pattern of the ansa spiralis was studied in 4 Mazama americana colons; the AA. observed that 2 (1 post-natal female and 1 foetuse male) had regular arrangements: 1 (male) were seen with three centripetal and three and a half centrifugal coils and the other' (female), with three and a half centripetal and four centrifugal coils; the remaining 2 cases ( 1 post-natal female and 1 young male) were seen with irregular spirals.

\section{REFERENCIAS BIBLIOGRAFICAS}

BORELLI, V. \& D"ERRICO, A. A. - Arranjo da ansa spiralis em fetos de caprinos. Rev. Fac. Med. vet. S. Paulo, 7 (2): 325-328, 1965.

BORELLI, V. \& FERNANDES FILHO, A. - Irregularidades da ansa spiralis do colon em caprinos. Rev. Fac. Med. vet. S. Paulo, 7 (2): 319-323, 1965. 
BORELLI, V. \& PEDUTI NETO, J. - Comportamento da ansa spiralis em bovinos de origem européia. Rev. Med. vet. S. Paulo, 2: 52-57, 1966-a

BORELLI, V. \& PEDUTI NETO, J. - Arranjos da ansa spiralis em fetos de Bos taurus. Rev. Med. vet. S. Paulo, 2: 99-102, 1966-b.

BORELLI, V. \& SANTIS PRADA, I. L. - Irregularidades da ansa spiralis do cólon em ovinos de raça Merino. Rev. Fac. Med. vet. S. Paulo, $7(3)$ : 521-526, 1966/67.

PAIVA, O. M. \& BORELLI, V. - Comportamento da ansa spiralis do cólon em bovinos azebuados. Rev. Fac. Med. vet., S. Paulo, $7(1)$ : 1-10, 1963/64-a.

PAIVA, O. M. \& BORELLI, V. - Disposiçōes incomuns da ansa spiralis do colon em bovinos azebuados. Rev. Fac. Med. vet., S. Paulo, 7 (1): 11-17, $1963 / 64-b$.

PAIVA, O. M. \& BORELLI, V. - Arranjo da ansa spiralis em fetos de bovinos azebuados. Rev. Fac. Med. vet., S. Paulo, 7 (1): 19-23, 1963/64-c.

PAIVA, O. M. \& BORELLI, V. - Disposição da ansa spiralis do cólon em caprinos. Folia clin. biol., S. Paulo, 34: 18-22, 1965.

PAIVA, O. M. \& BORELLI, V. - Comportamento da ansa spiralis do cólon em ovinos. Folia clin. biol., S. Paulo, 35: 57-61, 1966.

PEDUTI NETO, J.; BORELII, v. \& BOCALLETTI, D. - Comportamento dell'ansa spiralis in bufali. (Trabalho apresentado à XXIV Conferência Anual da Sociedade Paulista de Medicina Veterinária. S. Paulo, 1969).

SMITH, R. N. - The arrangement of the ansa spiralis of the sheep colon. J. Anat., London, 89 (2): 246-249, 1955. 